\title{
Mucoscopy of a Venous Lake
}

\author{
Abhijeet Kumar Jha ${ }^{1}$, Juhi Pathak ${ }^{2}$
}

1 Department of Skin \& V.D., Patna Medical College and Hospital, Patna, Bihar, India

2 Department of Conservative Dentistry and Endodontics, Buddha Institute of Dental Sciences and Hospital, Patna, Bihar, India

Key words: mucoscopy, venous lake

Citation: Jha AK, Pathak J. Mucoscopy of a venous lake. Dermatol Pract Concept. 2019;9(1):20-21. DOI: https://doi.org/10.5826/ dpc.0901a05

Published: January 31, 2019

Copyright: $@ 2019$ Jha et al. This is an open-access article distributed under the terms of the Creative Commons Attribution License, which permits unrestricted use, distribution, and reproduction in any medium, provided the original author and source are credited.

Funding: None.

Competing interests: The authors have no conflicts of interest to disclose.

Authorship: All authors have contributed significantly to this publication.

Corresponding author: Abhijeet Kumar Jha, MD, Department of Skin \& V.D., Patna Medical College and Hospital, Patna, Bihar, India.

Email: drabhijeetjha@gmail.com

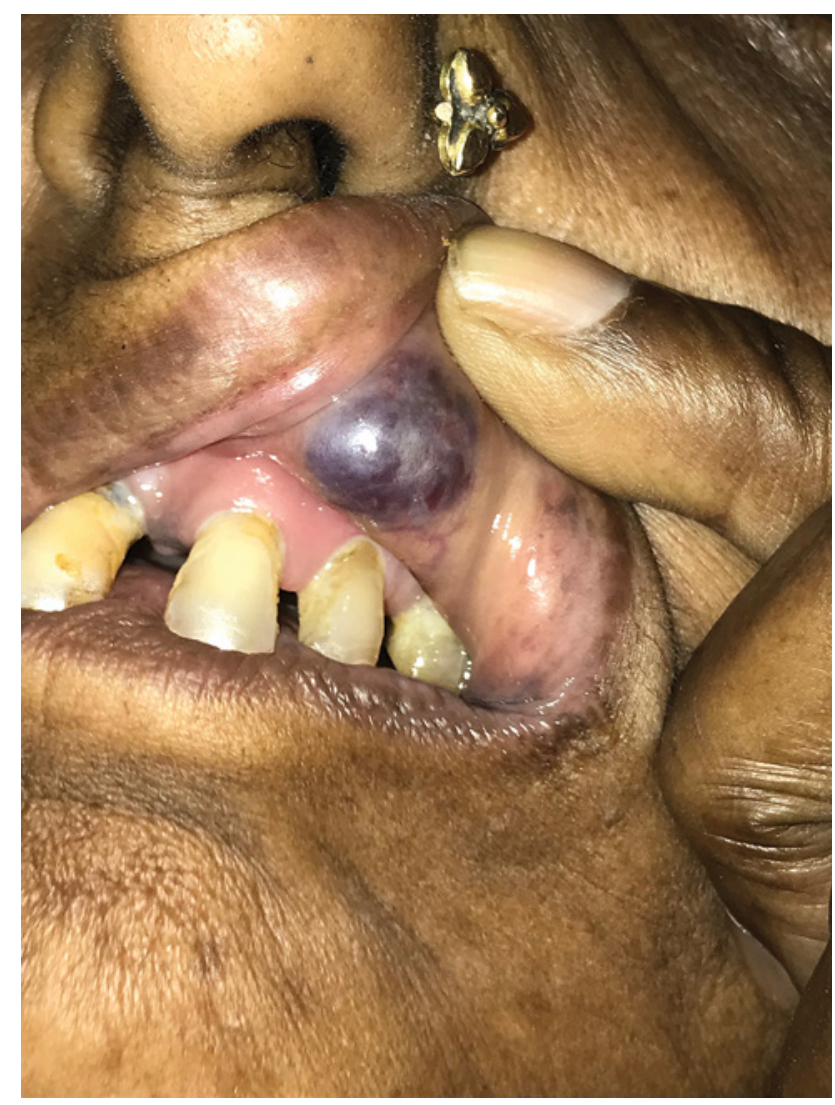

Figure 1. Single bluish swelling on the inner aspect of the upper lip. [Copyright: (2019 Jha and Pathak.]
A 56-year-old woman presented with a 5-year history of a single, painless, bluish swelling (Figure 1) over the inner aspect of the upper lip that began as a pea-sized lesion and gradually increased to the present size. There was no history of trauma or spontaneous bleeding. On examination, a single, violaceous, soft, compressible, nonindurated, nonpulsatile papule was present on the inner aspect of the upper lip. On diascopy, the lesion could be emptied of most of its blood content. Mucoscopy (polarized, 10x) revealed few red and blue lacunae with whitish veil (Figure 2). A diagnosis of venous lake was made.

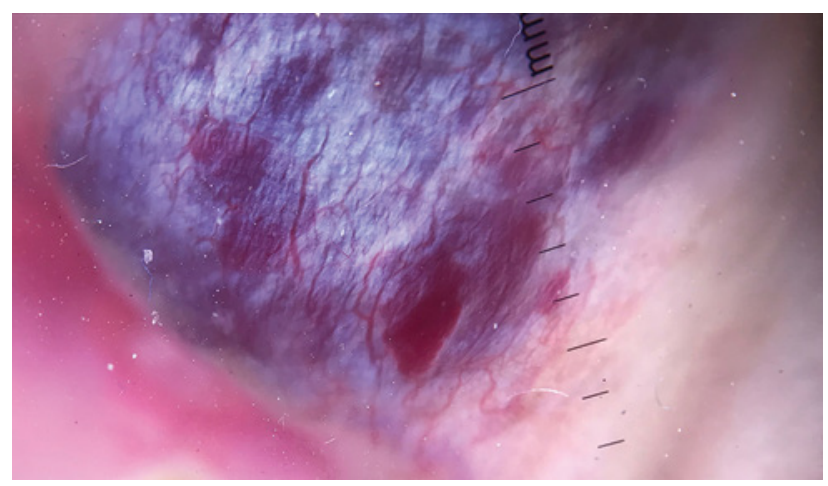

Figure 2. Mucoscopy (polarized, 10x) reveals few red and blue lacunae with whitish veil. [Copyright: @2019 Jha and Pathak.] 
Venous lakes, also known as "phlebectases" [1], are small $(0.2-1 \mathrm{~cm})$, generally solitary, soft, compressible, violaceous papules commonly found on sun-exposed areas, predominantly the vermilion border of the lips and ears. Lesions generally occur among the elderly [2]. Dermoscopically, venous lake can mimic cutaneous lymphangioma circumscriptum that displays 2 distinct patterns: yellow lacunae surrounded by pale septa without inclusion of blood and yellow to pink lacunae alternating with dark red or bluish lacunae, due to the inclusion of blood. Few lacunae can contain blood, which was characteristically accumulated in the lowest part of the lacuna, resulting in half-and-half lacuna [3]. To the best of our knowledge, this is the first report on mucoscopy in venous lake.

\section{References}

1. James W, Berger T, Elston D, eds. Andrews 'Diseases of the Skin: Clinical Dermatology. 10th ed. Philadelphia: Saunders; 2005:588.

2. Rapini RP, Bolognia JL, Jorizzo JL, eds. Dermatology. Vol. 2. St. Louis: Mosby; 2007:1624.

3. Jha AK, Lallas A, Sonthalia S. Dermoscopy of cutaneous lymphangioma circumscriptum. Dermatol Pract Concept. 2017;7(2):37-38. 